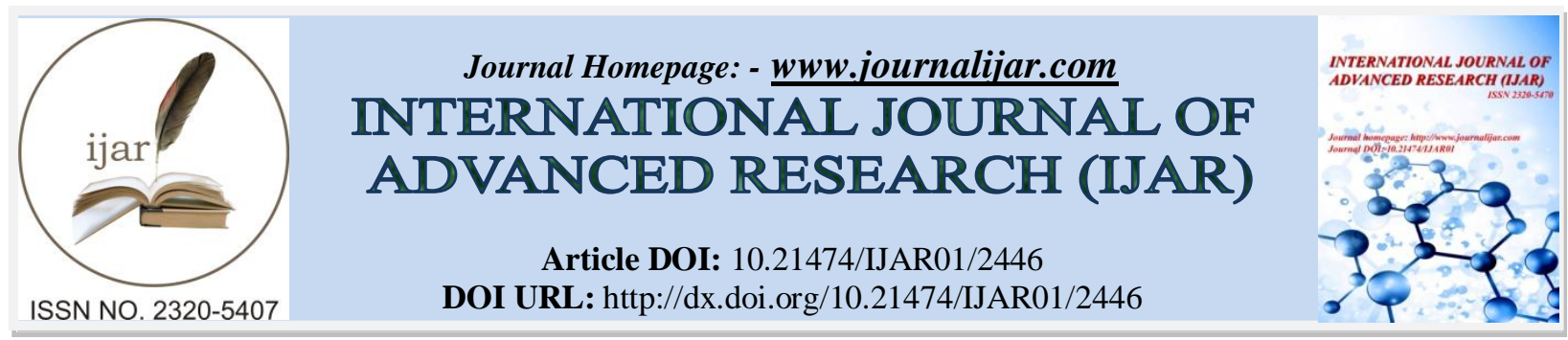

RESEARCH ARTICLE

\title{
SYNTHESIS OF COBALT SULPHIDE THIN FILM ELECTRODE BY MODIFIED CHEMICAL BATH DEPOSITION ROUTE AND ITS SUPERCAPACITORS PERFORMANCE.
}

\author{
${ }^{*}$ M. S. Sonawane ${ }^{1}$, P. K. Baviskar ${ }^{2}$ and R. S. Patil ${ }^{3}$.
}

1. Department of Physics, R. C. Patel Institute of Technology, Shirpur- 425405(M. S.) India.

2. Department of Physics, School of Physical Sciences, NMU, Jalgaon- 425001(M. S.) India.

3. Department of Physics, P. S. G. V. P. M’S Arts, Science \& Commerce College, Shahada- 425409 (M. S.) India.

\section{Manuscript Info}

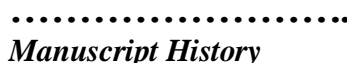

Received: 20 October 2016

Final Accepted: 22 November 2016

Published: December 2016

Key words:-

$\mathrm{CoS}$ thin films, Modified chemical bath deposition, Supercapacitor, KOH, Cyclic voltammetry, Charge-discharge, Impedance spectroscopy

\section{Abstract}

Cobalt Sulphide $(\mathrm{CoS})$ thin films were synthesized on stainless steel (SS) substrates using a modified chemical bath deposition route. The supercapacitive properties of this compound were studied by cyclic voltammetry, galvanostatic charge-discharge test and electrochemical impedance spectroscopy. The as-prepared $\mathrm{CoS}$ thin film electrode has excellent electrochemical capacitive characteristic with potential range 0 to $+0.7 \mathrm{~V} \mathrm{Vs} \mathrm{Ag} / \mathrm{AgCl}$ at constant concentration $2 \mathrm{M} \mathrm{KOH}$ solution. In cyclic voltammetry (CV) studies, effect of scan rate reveal that the $\mathrm{CoS}$ electrodes yield values of $531 \mathrm{Fgm}^{-1}$ and $244 \mathrm{Fgm}^{-1}$ for specific capacitance at scan rates of $10 \mathrm{mVs}^{-1}$ and $100 \mathrm{mVs}^{-1}$ respectively. Effect of concentration of electrolyte shows that, the specific capacitances values are increased from 60 to $351 \mathrm{Fgm}^{-1}$ with increasing the concentration $1 \mathrm{M}$ to $3 \mathrm{M}$ of $\mathrm{KOH}$. Stability studies at $50 \mathrm{mVs}^{-1}$ scan rate reveal that the specific capacitance values are decreased from 322 to $186 \mathrm{Fgm}^{-1}$ with increasing number of scan cycle. Charge-discharge behaviors have been observed that the supercapacitive parameters such as, specific energy (S.E.), specific power (S.P.) and coulombic efficiency $(\eta \%)$ are $11.4 \mathrm{Whkg}^{-1}$, $7.4 \mathrm{KWkg}^{-1}$ and $31 \%$, respectively. Impedance spectroscopic analysis revealed that the equivalent series resistance (ESR) is $1.8 \Omega$ at the imaginary axis.

Copy Right, IJAR, 2016,. All rights reserved.

\section{Introduction:-}

Electrochemical supercapacitor play an important role to fulfill the growing demand for power sources for modern communication facilities and transportation require because of characteristics [1]. Supercapacitors can divide into three general classes, double-layer capacitors, pseudocapacitors, and hybrid capacitors. In electrochemical capacitors, electric charges are stored by double-layer formation at the electrode/electrolyte interface (electric double-layer capacitors, EDLCs) or reversible faradaic reaction (pseudocapacitors). For EDLCs, porous carbon (high surface area) is commonly utilized as the electrode material with organic electrolytes while for pseudocapacitors, metal oxides/ sulphide and conducting polymers has been regarded as a promising electrode material due to its high specific capacitance. Supercapacitors can fill the energy and power gaps between the fuel cell and batteries. The major characteristics as envisaged for the electrochemical supercapacitors are; rapid rates of charge-discharge rate, high power densities and large cycle life [2,3]. 
Metal sulfides have recently emerged as new promising electrode materials for supercapacitor due to their excellent redox reversibility and relatively high capacitance. We have chosen Cobalt Sulphide as a electrode for supercapacitor because of its higher stability, high abundance, low cost, better safety, and environmental friendliness in comparison with other metal sulphide. Many techniques have been currently used in order to produce CoS thin films electrode. Feng Tao et al studied the $\mathrm{CoS}_{\mathrm{x}}$ was prepared by a very simply chemical precipitation method for high capacitance. The $\operatorname{CoS}_{\mathrm{x}}$ has excellent electrochemical capacitive characteristic with potential range -0.3 to $0.35 \mathrm{~V}$ Vs SCE. $\mathrm{CoS}_{\mathrm{x}}$ shows the deliver specific capacitance up to $474 \mathrm{Fg}^{-1}$ at $5 \mathrm{~mA}$ and $369 \mathrm{Fg}^{-1}$ at $50 \mathrm{~mA}$ chargedischarge current in $6 \mathrm{M} \mathrm{KOH}$ solution [4]. P. Justin and G. Ranga Rao, prepared sphere-like CoS nanostructures are synthesized in water/ethylene glycol mixed solvents by simple hydrothermal technique using L-cysteine amino acid. The bimodal porous sphere-like CoS shows high-rate capacitance from $363 \mathrm{Fg}^{-1}$ at $5 \mathrm{mV} \mathrm{s}^{-1}$ to $314 \mathrm{Fg}^{-1}$ at 50 $\mathrm{mV} \mathrm{s}^{-1}$. [5]. Shu-Juan Bao et al investigated a biomolecule-assisted hydrothermal process is developed to synthesize cobalt sulfide $(\mathrm{CoS})$. Researchers found that the $\mathrm{CoS}$ nanowire assembled by nanoflowers provides a very high specific capacitance $\left(508 \mathrm{Fg}^{-1}\right)$ with high specific energy, excellent discharge rate, and good stability [6]. Zusing Yang et al prepared a cobalt sulfide (CoS) hexagonal nanosheets (HNSs) onto transparent fluorine-doped tin oxide (FTO) substrates through a drop-dry process to prepare two types of supercapacitors (SCs); high rate and large perarea capacitance. The CoS HNSs provided high values of capacitance $326.4 \mathrm{Fg}^{-1}$. Researchers found that, the CoS HNSs electrodes exhibit excellent capacity properties, including high energy density $\left(13.2 \mathrm{Whkg}^{-1}\right)$, power density (17.5 $\left.\mathrm{kWkg}^{-1}\right)$, energy deliverable efficiency (81.3-85.3\%) [7]. Fulian Luo et al studied the pseudo-capacitive properties of the 3D flower-like $\mathrm{CoS}$ in $6 \mathrm{M} \mathrm{KOH}$ solution. A specific capacitance of $586 \mathrm{~F} \mathrm{~g}^{-1}$ is obtained at a charge-discharge current density of $1 \mathrm{Ag}^{-1}[8]$. J. Wang et al, prepared the nanosize cobalt sulfides were synthesized by one step chemical reaction method and it shows the best electrochemical properties. Cobalt sulfide nanopowders show promise as cathode active materials for lithium-rechargeable batteries [9].

In the present work, we report the synthesis of $\mathrm{CoS}$ thin films by modified chemical bath deposition (MCBD) method onto stainless steel (SS) substrate. The supercapacitive behavior of $\mathrm{CoS}$ film electrodes in $\mathrm{KOH}$ electrolyte was studied in terms of with respect to various parameters such as, scan rates, stability cycles, charging-discharging, electrochemical impedance spectroscopy (EIS) study and efficiency.

\section{Experimental details:-}

The stainless steel and glass substrates were used for the preparation of $\mathrm{CoS}$ thin film electrode. The stainless steel substrate was polished with polish paper to a rough finish, and ultrasonicated before use. In the present work, the MCBD method was used to deposit the CoS thin films on SS substrates which had been treated as described above.

The aqueous $(0.02 \mathrm{M}) \mathrm{CoSO}_{4}$ solution placed in a $50 \mathrm{ml}$ beaker used as cationic precursors. The $\mathrm{pH}$ of the solution was $\sim 8$. The $\mathrm{pH}$ of cationic precursors was raised with adding of $\mathrm{NH}_{3}$. The anionic precursors was $(0.05 \mathrm{M}) \mathrm{Na}_{2} \mathrm{~S}$ with $\mathrm{pH} \sim 12$ was placed in another $50 \mathrm{ml}$ beaker. For the deposition of CoS thin films a well cleaned glass or SS substrate was immersed in cationic precursors solution of Cobalt Sulphate for 60 second in which $\mathrm{Co}^{2+}$ ions were adsorbed on the surface of substrate. The substrate was rinsed with distilled water for 65 second to remove unabsorbed $\mathrm{Co}^{2+}$ ions. Then the substrate was immersed in anionic precursors of sodium disulphate solution for 60 second in which $\mathrm{S}^{2-}$ ions are reacted with adsorbed $\mathrm{Co}^{2+}$ ions on glass substrate. This was followed by rinsing again in distilled water for 65 second to remove unreacted $\mathrm{S}^{2-}$ ions. This completes one deposition cycle for deposition of $\mathrm{CoS}$ thin film. The $\mathrm{CoS}$ thin film deposited on glass or SS substrate by repeating such deposition cycle for 20, 25, 30, 35, 40, 45 and 50 times. The deposition carried out at $\sim 27^{\circ} \mathrm{C}$. The deposited CoS films were black, homogeneous with a good adherence to the substrate [10-14]. The thickness of the films was measured by weight difference method using sensitive microbalance.

The pseudocapactive properties of CoS thin films electrodes were studied using cyclic voltammetry (CV), galvanostatic charge/discharge test and EIS in $2 \mathrm{M} \mathrm{KOH}$ aqueous solution. These experiments were carried out with potentiostat/galvanostat (Princeton Applied Research, PARSTAT 4000). A typical three electrode cell was employed; $\mathrm{CoS}$ as a working electrode platinum wire as the counter electrode, and $\mathrm{Ag} / \mathrm{AgCl}$ used as the reference electrode. All electrochemical experiments were carried out at room temperature. 


\section{Results and discussion:- \\ Structural and Morphological Analysis:-}

The CoS thin films were grown onto glass substrates under optimized conditions using MCBD technique. The morphology and crystal structure of nanocrystalline $\mathrm{CoS}$ thin films were investigated by scanning electron microscopy and X-ray diffraction techniques respectively. Structural analysis of $\mathrm{CoS}$ thin films was carried out by $\mathrm{X}$-ray diffraction technique. Figure 1.1 shows typical XRD pattern of CoS thin film on glass substrate. The CoS thin film having four diffraction peaks at angles $2 \theta \sim 29.97^{\circ}, 53.32^{\circ}, 71.38^{\circ}$ and $88.89^{\circ}$ are correspond to (100), (110), (202) and (210) plane respectively. Comparison of $d$-values with JCPDS 65-0407 data for CoS shows that the material is $\mathrm{CoS}$ having hexagonal structure [4,11-15].

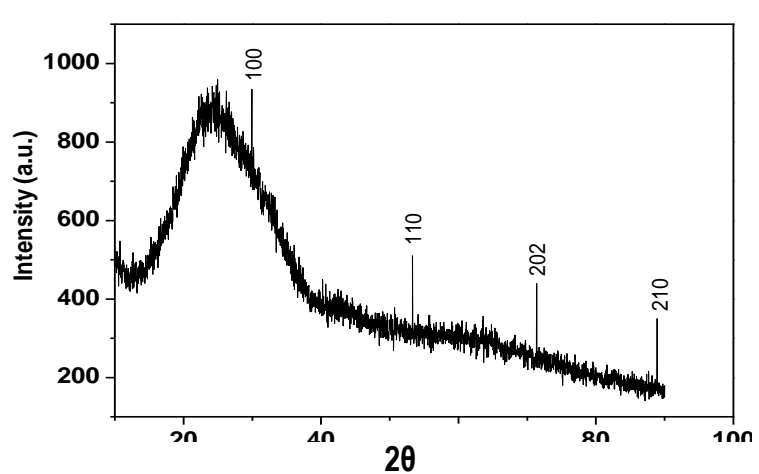

Figure 1.1:- XRD pattern of CoS thin films

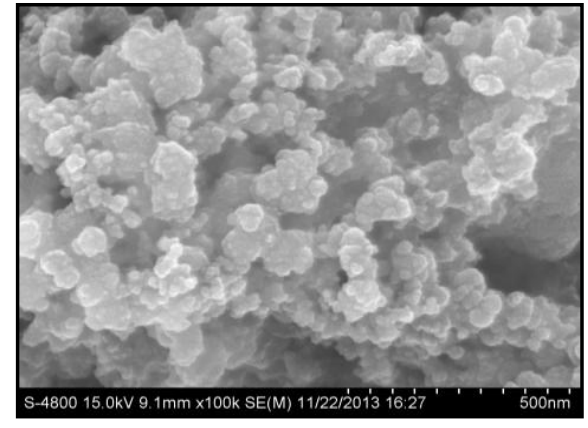

Figure 1.2:- The SEM image of as-deposited CoS film

Figure 1.2 shows the SEM image of the MCBD deposited CoS thin film. The substrate is well covered with fine elongated particles having different sizes. Surface also covered with small agglomerates of different sizes. It is difficult to find approximately size of particles. Some micro porous space between the fine particles can also be seen. The porosity of films can enhance the redox [15-16].

\section{Supercapacitive properties of the CoS thin film electrode:-}

Chemically deposited $\mathrm{CoS}$ electrodes were used in the electrochemical capacitor and their performances were tested using CV. To perform cyclic voltammetry tests a series of changing voltages at a constant sweep rate (dV/dt) is applied and the response current is recorded. The supercapacitive studies carried out by means of effect of scan rate and stability studies. The capacitance can be estimated by the following equation [17-23],

$$
C\left(V_{f}-V_{i}\right)=q=\frac{1}{v} \int_{V_{i}}^{V_{f}} I(V) d V
$$

Where, $\mathrm{C}$ is the total capacitance, I the current density $\left(\mathrm{A} / \mathrm{cm}^{2}\right), \mathrm{v}$ the sweep rate $(\mathrm{V} / \mathrm{s}), v_{i}$ the initial and $v_{f}$ the final voltages (V). The integral on the right hand side of equation (1.1) is the area under the CV. Thus, the total surface charge, (or total capacitance) of the deposit material can be estimated by evaluating the area under the capacitive current-voltage curve portion of a CV. The specific capacitance $\left(\mathrm{Fgm}^{-1}\right)$ of the electrode was obtained by dividing the capacitance to weight dipped in the electrolyte. The interfacial capacitance $\left(\mathrm{Fcm}^{-2}\right)$ was obtained by dividing the capacitance to area dipped in the electrolyte.

Cyclic voltamogram of the CoS electrode of thickness $0.00017 \mathrm{gm} / \mathrm{cm}^{2}$, in aqueous electrolyte $2 \mathrm{M}$ solution of $\mathrm{KOH}$ were studied in the voltage range of 0 to $+0.7 \mathrm{~V} \mathrm{Vs} \mathrm{Ag} / \mathrm{AgCl}$. The $\mathrm{KOH}$ electrolyte gave the largest current, which was greater than the other electrolytes. The area of working electrode was $1 \mathrm{~cm}^{2}$. The voltammetric responses of CoS electrode at different scan rates are shown in figure 1.3. It was found that the current under curve is slowly increased with scan rate. This showed that voltammetric currents are directly proportional to the scan rate of $\mathrm{CV}$, indicating an ideally capacitive behavior $[4-9,24,25]$. 


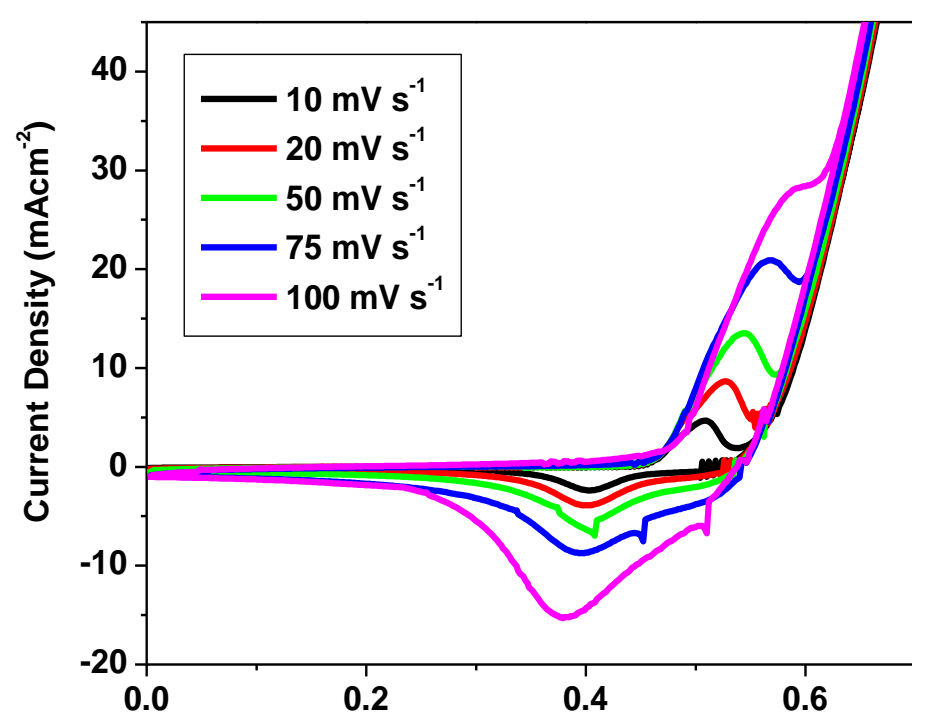

Figure 1.3:- The $\mathrm{CV}$ curves of $\mathrm{CoS}$ electrode at 10 to $100 \mathrm{mVs}^{-1}$ scan rates in $2 \mathrm{M} \mathrm{KOH}$ electrolyte

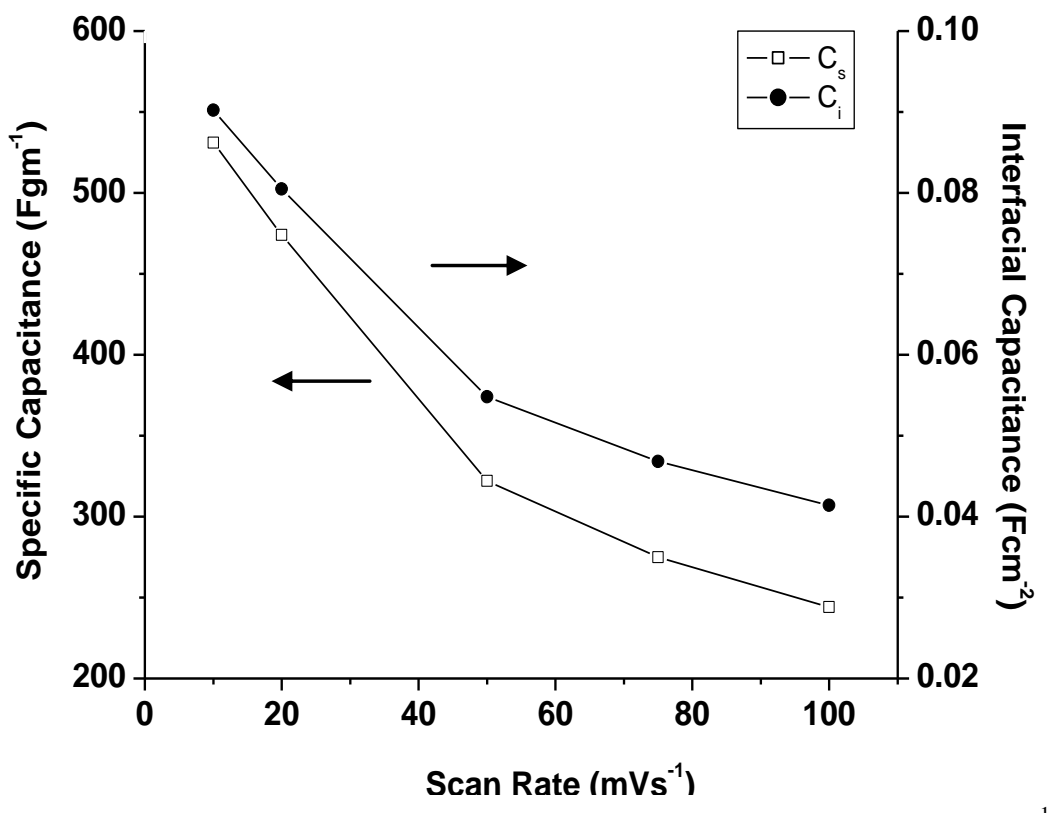

Figure 1.4:- The specific and interfacial capacitances of $\mathrm{CoS}$ electrode electrode at 10 to $100 \mathrm{mVs}^{-1} \mathrm{scan}$ rates in $2 \mathrm{M} \mathrm{KOH}$ electrolyte

Variation of specific capacitance and interfacial capacitance values with scan rate is shown in figure 1.4. The specific and interfacial capacitance values are decreased from 531 to $244 \mathrm{Fgm}^{-1}$ and 0.090 to $0.041 \mathrm{Fcm}^{-2}$ respectively, as the scan rate was increased from 10 to $100 \mathrm{mVs}^{-1}$. It is found that, with increase in scan rate, there is a slight decrease in the specific capacitance that is comparable to previously reported data. Maximum capacitance obtained for $\mathrm{CoS}$ at lower scan rate $\left(10 \mathrm{mVs}^{-1}\right)$ is $531 \mathrm{Fgm}^{-1}$.

Effect of Concentration of Electrolyte:-

The effect of concentration of $\mathrm{KOH}$ electrolyte was studied by keeping the constant scan rate and potential. The concentration of the $\mathrm{KOH}$ electrolyte was varied from $1 \mathrm{M}$ to $3 \mathrm{M}$. Figure 1.5 shows the $\mathrm{CV}$ curves of CoS electrode at $50 \mathrm{mVs}^{-1}$ scan rate within the potential range of 0 to $+0.7 \mathrm{~V} \mathrm{Vs} \mathrm{Ag/AgCl}$ in different concentrations of $\mathrm{KOH}$ 
electrolyte. The voltammograms were more distorted with the decrease in the electrolyte concentration. It is seen from the figure 1.5 that the current under curve increased as the concentration of $\mathrm{KOH}$ electrolyte increased from $1 \mathrm{M}$ to $3 \mathrm{M}$. For the further increase in the concentration of electrolyte, there was peel off of the electrode material from the substrate.

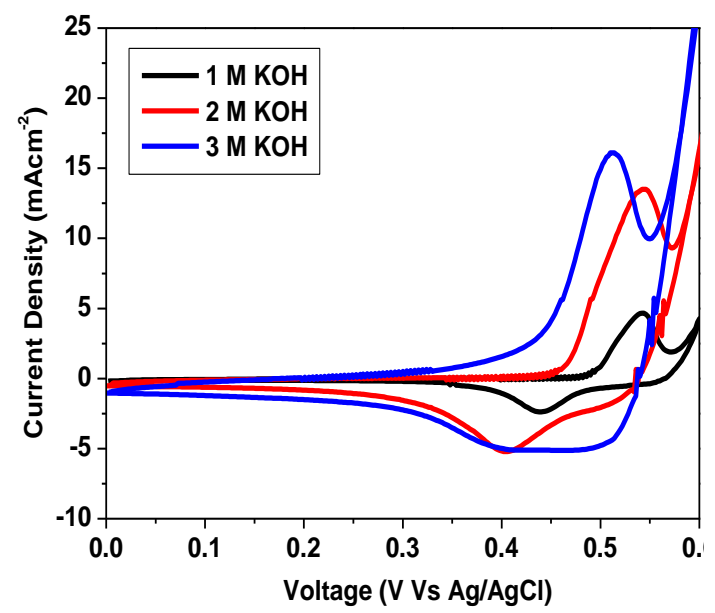

Figure 1.5:- The $\mathrm{CV}$ curves of $\mathrm{CoS}$ electrode with $50 \mathrm{mVs}^{-1}$ scan rate at different concentrations of $\mathrm{KOH}$ electrolyte

As the $\mathrm{KOH}$ concentration is lowered, the current peaks become broader and are shifted in the positive direction for both the anodic and cathodic processes. The specific and interfacial capacitances were increased with increasing the concentration of electrolyte. The specific and interfacial capacitance values are increased from 60 to $351 \mathrm{Fgm}^{-1}$ and 0.01 to $0.06 \mathrm{Fcm}^{-2}$ respectively. The optimal capacitance is obtained at $2 \mathrm{M} \mathrm{KOH}$ electrolyte. The CoS electrode exhibit high specific capacitances is $322 \mathrm{Fgm}^{-1}$ and interfacial capacitances is $0.055 \mathrm{Fcm}^{-2}$ at $2 \mathrm{M} \mathrm{KOH}$ electrolyte.

\section{Stability Studies:-}

Stability of CoS electrode in $2 \mathrm{M} \mathrm{KOH}$ was tested by CV. Figure 1.6 shows the CV curves for $5^{\text {th }}$ and $250^{\text {th }}$ cycle. We found that our system can withstand about 250 cycles without a significant decrease in the capacity, illustrating the fairly stable nature of a $\mathrm{CoS}$ electrode in energy storage application. From Figure, the specific and interfacial capacitance values are decreased from 322 to $186 \mathrm{Fgm}^{-1}$ and 0.055 to $0.032 \mathrm{Fcm}^{-2}$ respectively. The specific and interfacial capacitance values are decreased in small amount with the number of cycles due to the loss of active material.

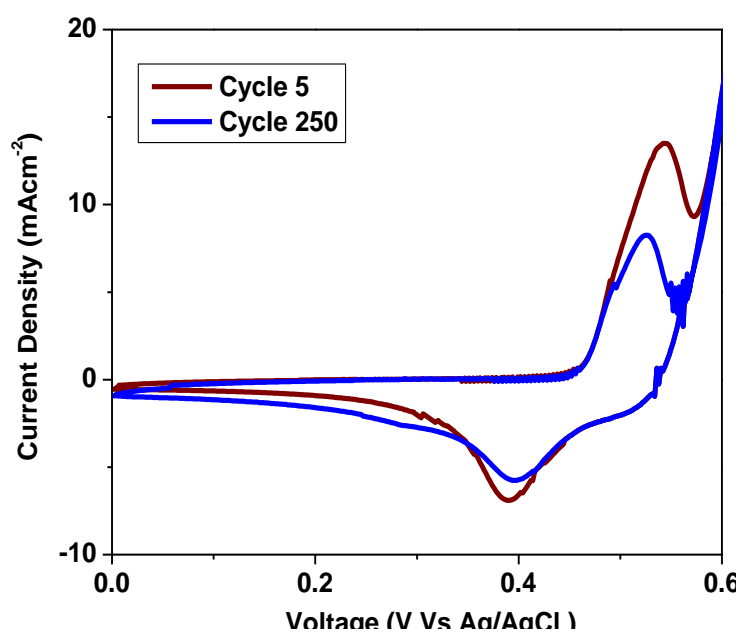

Figure 1.6:- The $\mathrm{CV}$ curves of $\mathrm{CoS}$ electrode in $2 \mathrm{M} \mathrm{KOH}$ electrolyte with scan rate of $50 \mathrm{mV} \mathrm{s}^{-1}$ for 5 and 250 cycles. 


\section{Galvanostatic Charge-Discharge Studies:-}

The CoS electrode was subjected to galvanostatic charge-discharge cycling between 0 and $+0.7 \mathrm{~V}$ in $2 \mathrm{M} \mathrm{KOH}$ solution at a current density of $1 \mathrm{mAcm}^{-2}$. Typical curves of potential variation with time of cycling are shown in figure 1.7, it can be seen that, the nonsymmetric behavior of voltage-time curve was seen, that is IR drop was observed. The discharge profile showed two parts; a resistive component arising from the sudden voltage drop (linear portion parallel to y-axis) representing the voltage change due to the internal resistance and a capacitive component (curved portion) related to the voltage change due to the change in energy within the capacitor. The specific energy (E), and specific power (P) and coulomb efficiency $(\eta \%)$ are calculated using following equations $[7,22]$,

$$
\begin{gathered}
\mathrm{E}=\left(\frac{0.5}{3.6}\right) \mathrm{C}_{\mathrm{s}}(\Delta \mathrm{V})^{2} \\
\mathrm{P}=\left(\frac{E}{t_{d}}\right)
\end{gathered}
$$

And, Columbic efficiency $(\%) \eta=\left(\frac{t_{d}}{t_{c}}\right) \times 100$

Where, $C_{s}$ is the specific capacitance and $\Delta V(\mathrm{~V})$ is the voltage window. $t_{d}$ is discharging time (s), $t_{c}$ is charging time (s).

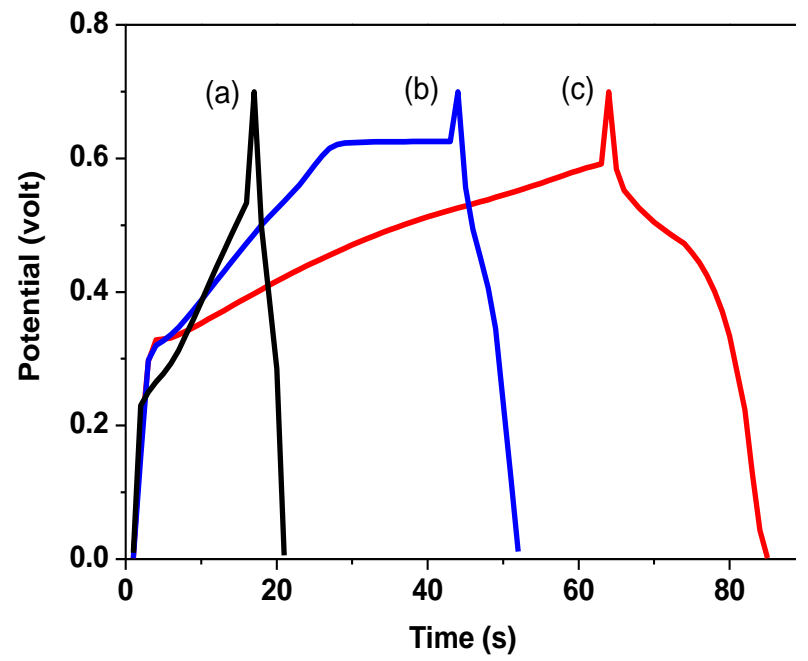

Figure 1.7:- Charging-discharging behavior of CoS electrode at a current density of (a) 3, (b) 2, (c) $1 \mathrm{mAcm}^{-2}$ in $2 \mathrm{M} \mathrm{KOH}$ electrolyte

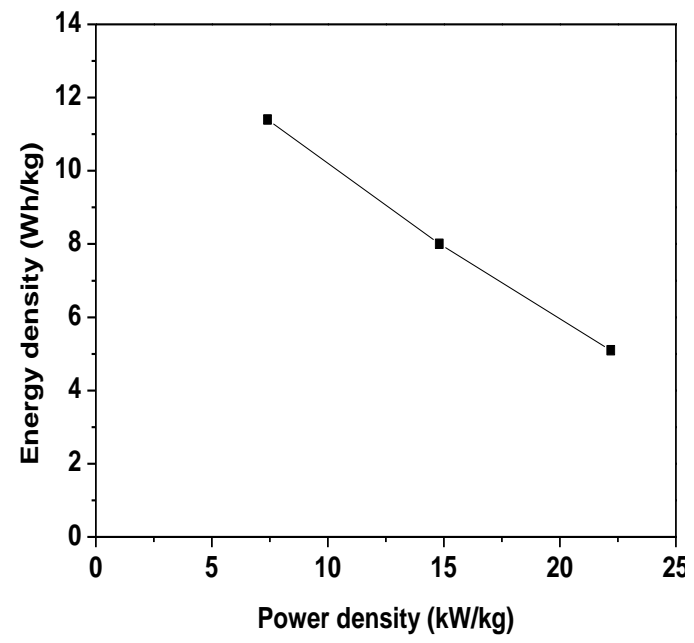

Figure 1.8:- Variation of energy density with power density values of CoS electrode at different current densities 
The capacitance, energy density and power density of the CoS electrode were calculated using equation (1.1), (1.2) and (1.3). The specific capacitance value is 168,118 and $76 \mathrm{Fgm}^{-1}$ for CoS thin film electrode at current density 1,2 and $3 \mathrm{mAcm}^{-2}$, respectively. The maximum energy density of $11.4 \mathrm{Whkg}^{-1}$ and power density of $7.4 \mathrm{kWkg}^{-1}$ was obtained at a current density $1 \mathrm{mAcm}^{-2}$. This increase in specific energy and power may be due to increased time for charging and discharging of capacitor. The energy efficiency, $31 \%$ was obtained. Variation of energy density with power density values of $\mathrm{CoS}$ electrode at different current densities is shown in figure 1.8.

Electrochemical impedance analysis (EIS studies):-

Electrochemical impedance spectroscopy, a powerful technique for the investigation of the capacitive behavior of electrochemical cells, has been also used to characterize our materials. Figure 1.9 presents Nyquist plots obtained for as deposited $\mathrm{CoS}$ electrodes. It displays a semicircle in the high frequency and a linear curve in the low-frequency region. The semicircle in the high-frequency region is related to the reaction kinetics at the electrode and electrolyte interfaces $[4,8,26,27]$. The linear curve at the low-frequency region can be attributed to the diffusion controlled process in the electrolyte. The initial non-zero intercept in high frequency regime at the beginning of the semicircle and is due to the electrical resistance of the electrolyte $\left(R_{\mathrm{ele}}\right)$. The values for equivalent series resistance (ESR) for as deposited CoS thin films are $1.8 \Omega$.

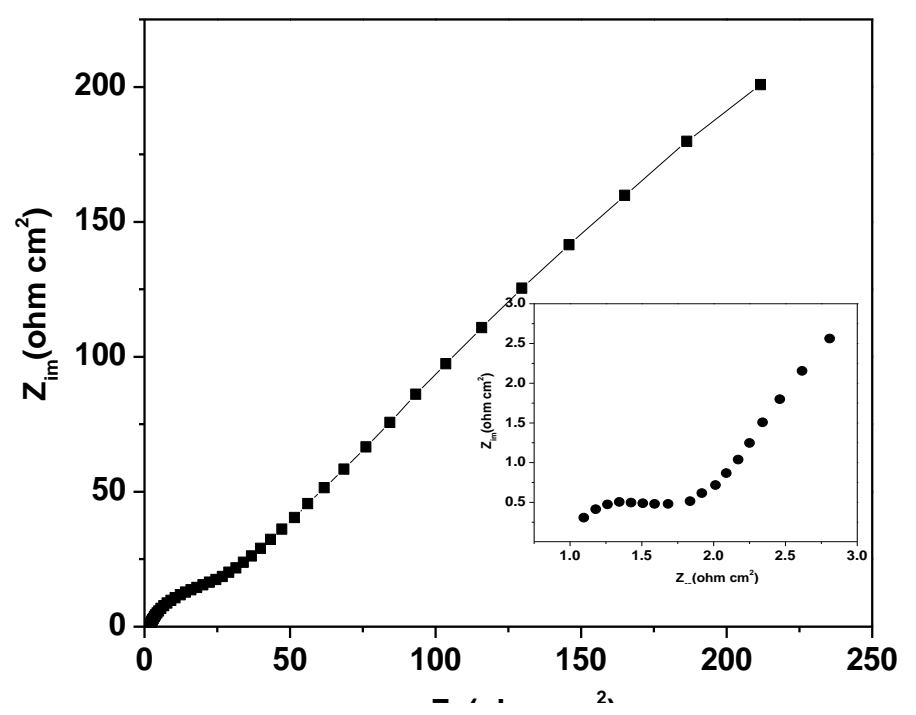

Figure 1.9:- Nyquist plots of $\mathrm{CoS}$ electrode in $2 \mathrm{M} \mathrm{KOH}$

\section{Conclusion:-}

In conclusion, $\mathrm{CoS}$ films have been prepared successfully at room temperature by MCBD method and used in supercapacitors. The XRD measurements confirmed that the CoS was deposited in the form of polycrystalline. The SEM analysis showed that the substrate is well covered with different sizes fine elongated particles. The as-prepared $\mathrm{CoS}$ thin film electrode has excellent electrochemical capacitive characteristic with potential range 0 to $+0.7 \mathrm{~V}$ Vs $\mathrm{Ag} / \mathrm{AgCl}$ at constant concentration $2 \mathrm{M} \mathrm{KOH}$ solution. The electrochemical study revealed that the Cobalt Sulphide electrode showed high specific capacitance of $531 \mathrm{Fgm}^{-1}$. The specific energy (E), specific power $(\mathrm{P})$ and coulomb efficiency $(\eta \%)$ was $11.4 \mathrm{Whkg}^{-1}$ and $7.4 \mathrm{kWkg}^{-1}$, and $31 \%$, respectively. Impedance spectroscopic analysis revealed that the ESR is $1.8 \Omega$ at the imaginary axis.

Although, the performance of these electrodes is poor as compared to conventional expensive electrodes, the further research to overcome technical aspects will definitely bring them to raise the efficiency of the supercapacitor.

\section{Acknowledgement:-}

Authors are thankful to Principal, PSGVPM'S ASC College, Shahada for his constant support throughout this work. MSS is thankful to the Principal, R. C. Patel Institute of Technology, Shirpur for promoting for paper publication. 
The authors would like to thank the Department of Physics, School of Physical Sciences, NMU, Jalgaon and Nano Materials and Device Laboratory, Applied Physics Department, VNIT, Nagpur for the provision of characterization facilities.

\section{References:-}

1. M. Jayalakshmi, K. Balasubramanian, (2008): Review Simple Capacitors to Supercapacitors - An Overview. Int. J. Electrochem. Sci., 3:1196-1217.

2. http://en.wikipedia.org/wiki/Electric_double-layer_capacitor

3. Jong H. Jang et al.,(2006): Supercapacitor Performance of Hydrous Ruthenium Oxide Electrodes Prepared by Electrophoretic Deposition. Journal of The Electrochemical Society, 153 (2):A321-A328.

4. Feng Tao et al.,(2007): Electrochemical characterization on cobalt sulfide for electrochemical supercapacitors. Electrochemistry Communications, 9:1282-1287.

5. P. Justin, G. Ranga Rao,(2010): CoS spheres for high-rate electrochemical capacitive energystorage application. International Journal of Hydrogen Energy, 35:9709-9715.

6. Shu-Juan Bao et al.,(2008): Biomolecule-assisted synthesis of cobalt sulfide nanowires for application in supercapacitors. Journal of Power Sources, 180: 676-681.

7. Zusing Yang et al.,(2011): Supercapacitors incorporating hollow cobalt sulfide hexagonal nanosheets. Journal of Power Sources, 196: 7874-7877.

8. F. Luo et al., (2014): Rapid synthesis of three-dimensional flower-like cobalt sulfide hierarchitectures by microwave assisted heating method for high-performance supercapacitors. Electrochimica Acta, 123:183-189.

9. J. Wang et al., (2006): Synthesis and characterization of nanosize cobalt sulfide for rechargeable lithium batteries. Journal of Power Sources, 159: 287-290.

10. R. S. Mane, C. D. Lokhande,(2000): Review Chemical deposition method for metal chalcogenide thin films. Mater. Chem. Phys. 65:1-31.

11. S. D. Sartale, C. D. Lokhande, (2000): Deposition of cobalt sulphide thin films by successive ionic layer adsorption and reaction (SILAR) method and their characterization. IJPAP, 38:48-52.

12. M. S. Sonawane et al, (2014): Nanocrystalline CoS thin films prepared by modified chemical bath deposition method. Journal of Chemical, Biological and Physical Sciences, 4:2416-2423.

13. P. K. Basu, P. Pramanik, (1986): Solution growth technique for the deposition of cobalt sulphide thin film. J. Mater. Sci. Lett., 5:1216-1218.

14. S.T. Mane, S.S. Kamble, L.P. Deshmukh, (2011): Cobalt sulphide thin films: Chemical bath deposition, growth and properties. Mater. Lett., 65:2639-2641.

15. S. Ariponnammal, T. Srinivasana., (2013): Growth and characterization of cobalt sulphide nanorods. Res. J. Recent. Sci., 2:102-105.

16. Yu Zhenrui et al., (2002): CoS thin films prepared with modified chemical bath deposition. Thin Solid Films, 415:173176.

17. E. E. Kalu et al.,(2001): Cyclic voltammetric studies of the effects of time and temperature on the capacitance of electrochemically deposited nickel hydroxide. J. Power Sources, 92:163-167.

18. B.Vidhyadharan et al.,(2014): High performance supercapacitor electrodes from electrospun nickel oxide nanowires. Journal of Alloys and Compounds, 610: 143-150.

19. B.R.Sankapal et al.,(2014): Presenting highest supercapacitance for TiO2/MWNTs nanocomposites: Novel method. Chemical Engineering Journal, 247:103-110.

20. Venkat Srinivasan, John W. Weidner,(2002): Capacitance studies of cobalt oxide films formed via electrochemical precipitation. J. of Power Sources, 108: 15-20.

21. S.G.Kandalkar et al.,(2008): Preparation of cobalt oxide thin films and its use in supercapacitor application. Applied Surface Science, 254: 5540-5544.

22. Shen Ming Chen et al., (2014): Recent advancements in electrode materials for the high-performance electrochemical supercapacitors: A Review. Int. J. Electrochem. Sci., 9: 4072-4085.

23. R Ramya, M. V. Sangaranarayanan, (2008): Analysis of polypyrrole-coated stainless steel electrodes - Estimation of specific capacitances and construction of equivalent circuits. J. Chem. Sci., 120: 25-31.

24. Chia-Ying Chen et al.,(2012): Carbon nanotubes/cobalt sulfide composites as potential high-rate and high-efficiency supercapacitors. Journal of Power Sources, 215: 43-47.

25. Qinghong Wang et al., (2011): Facile synthesis and superior supercapacitor performances of three-dimensional cobalt sulfide hierarchitectures. Cryst Eng Comm, 13: 6960-6963.

26. S. G. Kandalkar et al., (2011): Cobalt-nickel composite films synthesized by chemical bath deposition method as an electrode material for supercapacitors. J Mater Sci., 46: 2977-2981.

27. C. Arbizzani et al.,(2001): New trends in electrochemical supercapacitors. Journal of Power Sources, 100: 164-170. 